\title{
Study of Bone Marrow Lymphocyte Subset in Acute Myeloid Leukemia
}

\author{
Prasad Dange $^{1}$ Seema Tyagi ${ }^{2} \quad$ Richa Juneja $^{3} \quad$ Tulika Seth $^{2}$ Renu Saxena ${ }^{4}$
}

${ }^{1}$ Department of Pathology, Grant Government Medical College, Mumbai, Maharashtra, India

2 Department of Hematology, All India Institute of Medical Science, New Delhi, India

${ }^{3}$ Department of Pathology, All India Institute of Medical Sciences, Nagpur, Maharashtra, India

${ }^{4}$ Department of Hematopathology, Medanta Hospital, Gurugram, Haryana, India

J Lab Physicians 2022;14:151-156.

\begin{abstract}
Address for correspondence Prasad Dange, MD, DM, Department of Hematology, All India Institute of Medical Sciences, Raipur, 492099, Chhattisgarh, India (e-mail: prasaddange88@gmail.com).
\end{abstract}

\begin{abstract}
Keywords

- acute myeloid leukemia

- immunity

- flowcytometry

- lymphocyte subset

Introduction Acute myeloid leukemia (AML) is a heterogenous disorder consisting of clonal expansion of myeloblasts. Tumor immunity plays an important part in the pathobiology of AML. Understanding the components of tumor immunity is important for understanding tumor pathogenesis and the principles of immunotherapy.

Methods We studied 41 patients with AML, for total lymphocyte, CD4 positive helper T cells, CD8 positive cytotoxic T cells, and CD16/56 positive natural killer (NK) cells proportion. Quantification was done on bone marrow aspirate sample by flowcytometry. Whenever available, post induction bone marrow was also analyzed for the lymphocyte subset.

Results No significant difference was noted in the percentage of blasts among the three risk categories: favorable, intermediate, and adverse. However, there was significant difference in the total lymphocyte among the risk stratification groups, being highest in the favorable group and lowest in the adverse group. CD8 positive cytotoxic T cells were significantly less in Acute Promyelocytic Leukemia (APML) cases $(p=0.001)$. Total lymphocytes were, however, more numerous in APML $(p=0.005)$. NK cell proportion was not significantly different between APML and non-APML patients. On completion of induction chemotherapy, bone marrow samples for 12 patients could be processed for lymphocyte subset. On comparing the baseline against the post induction bone marrow, it was observed that there was significant increment in the proportion of CD4 positive T lymphocytes ( $p=0.046)$.

Conclusion There is a difference in lymphocyte subset amongst patients with AML. Larger studies including functional aspects are needed to better define the role of lymphocytes in disease pathogenesis.
\end{abstract}

published online July 15, 2021
DOI https://doi.org/

$10.1055 / \mathrm{s}-0041-1733304$. ISSN 0974-2727.
(C) 2021. The Indian Association of Laboratory Physicians. All rights reserved.

This is an open access article published by Thieme under the terms of the Creative Commons Attribution-NonDerivative-NonCommercial-License, permitting copying and reproduction so long as the original work is given appropriate credit. Contents may not be used for commercial purposes, or adapted, remixed, transformed or built upon. (https://creativecommons.org/ licenses/by-nc-nd/4.0/)

Thieme Medical and Scientific Publishers Pvt. Ltd., A-12, 2nd Floor, Sector 2, Noida-201301 UP, India 


\section{Introduction}

Acute myeloid leukemia (AML) is a heterogenous disorder consisting of clonal expansion of myeloblasts in peripheral blood, bone marrow, or other tissue. AML is characterized by a large variety of cytogenetic, molecular, and epigenetic alterations which have important impact on the disease biology and consequently on the patient outcome. ${ }^{1}$ These alterations have been proven to be powerful prognostic markers and have been included in the risk stratification of $\mathrm{AML}^{2}{ }^{2}$ However, there has been increasing realization that microenvironment plays an important role in the pathobiology of the disease.

There is close interaction between the bone marrow microenvironment and the leukemic blasts. There is active modification of the microenvironment by the leukemic blasts that supports the blasts survival and proliferation and impedes normal hematopoiesis. ${ }^{3}$ Another important component of the microenvironment includes the immune system. Various components of the immune system including lymphocytes, macrophages, etc. play important role in tumor pathogenesis. The role of the immunity is highlighted by the graft versus leukemia effect seen in the allogenic stem cell transplant in patients with acute leukemia. ${ }^{4}$ In view of these observations, the study of the immune cells in leukemic patients has been an active area of research in the recent past.

Quantitative as well as qualitative analysis of the invading lymphocytes is important for proper understanding of the tumor immune surveillance. The literature comparing the prechemotherapy and post induction bone marrow is scant. The study aimed to study the relative proportion of $\mathrm{T}$ cell subsets and NK cells in bone marrow of AML patients using flowcytometry and compare it with the post induction marrow, whenever available.

\section{Materials and Methods}

\section{Patient Population}

The study was a prospective observational study. The study was approved by the Institutional Review Board. Forty-one patients of AML were studied between March 2018 and July 2019. AML was diagnosed based on peripheral blood and bone marrow morphology, cytochemistry and flowcytometry. Final diagnosis was done as per 2016 WHO classification of hematolymphoid neoplasms and risk stratification was done as per 2017 European Leukemia Network prognostic model. ${ }^{2}$ The eligible patients received $3+7$ induction chemotherapy consisting of daunorubicin and cytarabine, respectively.

\section{Flowcytometry Analysis}

The bone marrow sample received for diagnostic work-up was also processed for assessment of lymphocyte subset. Stain-Lyse-wash protocol was used. The cells were stained with CD45-PerCP/Cy5.5 (Clone: H130), CD3-PE/Cy7 (Clone: UCHT1), CD4-PE (Clone: OKT4), CD8-FITC (Clone: SK1), CD16-APC/Cy7 (Clone: 3G8), and CD56-APC (Clone: HCD56).
All the antibody conjugates were procured from BioLegend. At least 30,000 events were acquired.

Flowcytometric analysis was done on BD FACS Canto II (Becton Dickinson, San Jose, California, United States) using software BD FACSDiva.

\section{Data Analysis}

Sequential gating strategy was used to analyze the lymphocyte subset. First, the doublets were excluded based on FSC-A versus FSC-H plot. Next, the lymphocyte cluster was carefully gated on CD45 versus side scatter plot ( - Fig. 1). The gated lymphocyte population was further analyzed to differentiate into following subsets:

- Proportion of lymphocyte of all events, including the erythroid cells.

- Proportion of Helper T cells (CD4 positive), cytotoxic T cells (CD8 positive), and NK cells among all lymphocytes.

- Ratio of CD4 to CD8 cells.

Relevant clinical data was collected that included patient characteristics and complete blood count at presentation. Bone marrow blast percentage, cytogenetic findings, and molecular mutation analysis (whenever done) were also noted. The eligible patients received the standard $3+7$ induction chemotherapy comprising of daunorubicin and cytarabine. Daunorubicin $\left(60 \mathrm{mg} / \mathrm{m}^{2} / \mathrm{d}\right)$ was administered as rapid intravenous infusion for 3 days while cytarabine $\left(100 \mathrm{mg} / \mathrm{m}^{2} / \mathrm{d}\right)$ was administered as continuous infusion
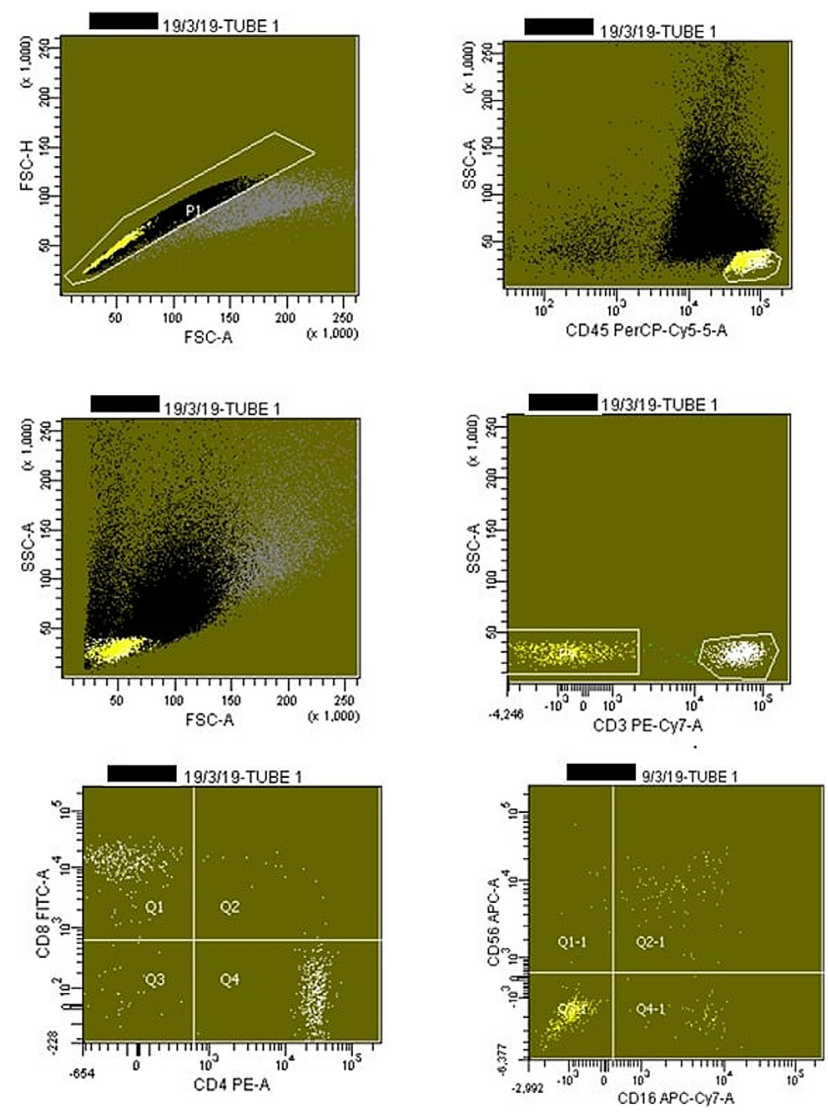

Fig. 1 Lymphocyte subset analysis in pretreatment bone marrowCD45 versus side scatter plot shows mostly blasts and lymphocytes. 
over 7 days. Acute promyelocytic leukemia patients received induction of all trans retinoic acid $\left(45 \mathrm{mg} / \mathrm{m}^{2} / \mathrm{d}\right)$ and arsenic trioxide $\left(0.15 \mathrm{mg} / \mathrm{m}^{2} / \mathrm{d}\right)$. Daunorubicin $\left(60 \mathrm{mg} / \mathrm{m}^{2} / \mathrm{d}\right)$ for 3 days was added for high-risk patients. The outcome of the induction regimen was noted for those patients who were admitted and were started on induction chemotherapy.

\section{Statistical Analysis}

Categorical variables were presented in number and percentage (\%) and continuous variables were presented as mean \pm standard deviation and median. Normality of data was tested by Kolmogorov-Smirnov test. Quantitative variables were compared using Independent $t$-test/Mann-Whitney test (when the datasets were not normally distributed) between the two groups and ANOVA/Kruskal-Wallis test between more than two groups. Paired t-test/Wilcoxon ranked sum test was used for comparison between pre and post induction. A $p$-value of $<0.05$ was considered statistically significant. The data was entered in MS EXCEL spreadsheet and analysis was done using Statistical Package for Social Sciences (SPSS) version 21.0.

\section{Results}

\section{Baseline Patient Characteristics}

Study included a total of 41 patients comprising of 23 males and 18 females. The median age was 29 years, the age range being 6 years to 65 years. The duration of symptoms ranged from 2 weeks to 10 months. Out of 41,28 patients had fever as one of their presenting complaints. All except two had easy fatigability or weakness. Twenty-five patients had bleeding symptoms, including two with gastrointestinal bleed and three with menorrhagia. Thirty-seven out of 41 patients presented with a hemoglobin level less than $100 \mathrm{~g} / \mathrm{L}$. The peripheral blood total leucocyte count varied widely (range: $0.25 \times 10^{9} / \mathrm{L}$ to $180 \times 10^{9} / \mathrm{L}$ ). A total of eight patients presented with hyperleukocytosis with a TLC of more than $100 \times 10^{9} / \mathrm{L}$. Thirty-two patients had thrombocytopenia (less than $100 \times 10^{9} / \mathrm{L}$ ). Bone marrow aspirate done at diagnosis showed variable blast percentage ranging from 22 to $94 \%$ (median 75\%). There were eight cases of acute promyelocytic leukemia, confirmed by presence of PML-RARA fusion transcript by reverse transcription polymerase chain reaction (RT-PCR). On karyotyping of other 33 patients, 17 showed normal karyotype, 6 patients were positive for $\mathrm{t}(8 ; 21)$ (q22; q22). No metaphase was obtained in two patients, one patient was positive for $\mathrm{t}(9 ; 22)(\mathrm{q} 34 ; \mathrm{q} 11.2),-7$ (monosomy 7 ) each. Rest of the patients showed nonspecific abnormalities. Molecular mutation could be performed in 21 cases, out of which 8 were PML-RARA fusion transcript positive. Two patients were NPM1 mutated, two showed FLT3 mutation (one had low allele burden), and one was c-kit mutation positive. The patient with $\mathrm{t}(9 ; 22)$ ( $\mathrm{q} 34 ; \mathrm{q} 11.2)$ had BCR-ABL fusion transcript of p210.

\section{Lymphocyte Subset Analysis on Flowcytometry}

For 41 cases analyzed, the total lymphocyte and the proportion of subsets are shown in - Table 1.

\section{Lymphocyte Subset and Risk Stratification}

Based on the cytogenetic and molecular mutation data, favorable, intermediate, and adverse prognostic groups comprised of 14,22 , and 5 patients, respectively.

There was no significant difference in the bone marrow blast percentage among the three groups $(p=0.631)$. However, there was significant difference in the total lymphocyte percentage among the three groups, being highest in the favorable group and lowest in the adverse risk group ( $p=$ 0.005). There was no significant correlation for the lymphocyte subsets, i.e., CD4 positive, CD8 positive, and NK cells among the three groups ( $\mathbf{- T a b l e ~} \mathbf{2}$ ).

\section{Lymphocyte Subset in APML and Non-APML Cases}

There were eight cases of acute promyelocytic leukemia, that were positive for PML-RARA fusion transcript by RT-PCR. CD8 positive cytotoxic T cells were significantly less in APML cases $(p=0.001)$. Total lymphocytes were, however, significantly higher in APML $(p=0.005)$. CD4 positive helper T cells were more in number in non-APML, however, the difference was not statistically significant $(p=0.068)$. No statistically significant difference was observed in the NK cell proportion and the CD4:CD8 ratio (- Table 3 ).

\section{Lymphocyte Subsets in Post-Induction Marrow and Its Comparison with the Baseline}

Out of 41 cases, 24 cases were admitted for induction therapy. Fourteen out of 24 cases achieved remission (including four APML cases), 2 out of 24 were refractory to induction therapy and 8 cases expired during induction therapy (including four APML cases).

No significant difference in baseline marrow was observed in the proportion of total lymphocytes or any of the lymphocyte subset between patients who achieved induction remission as against those who died during induction or had refractory disease.

Post remission bone marrow samples for 12 patients could be processed for lymphocyte subset. On comparing the pretreatment (baseline) bone marrow against the post induction bone marrow for these 12 cases, there was significant increment in the proportion of the CD4 positive $T$ lymphocytes $(p=0.046$ ). No significant change was observed for total lymphocytes and other subsets.

Table 1 Total lymphocyte and subset proportion in bone marrow in AML patients $(n=41)$

\begin{tabular}{|l|l|l|}
\hline Lymphocyte subset & Median (Range) & Mean \pm SD \\
\hline CD4:CD8 ratio & $0.91(0.42-1.94)$ & $1.04 \pm 0.36$ \\
\hline $\begin{array}{l}\text { CD4 positive \% } \\
\text { (of all lymphocytes) }\end{array}$ & $31.4(16.4-47.3)$ & $31.2 \pm 7.3$ \\
\hline $\begin{array}{l}\text { CD8 positive \% } \\
\text { (of all lymphocytes) }\end{array}$ & $32.9(15.9-51.7)$ & $32.7 \pm 10.1$ \\
\hline $\begin{array}{l}\text { NK cells \% } \\
\text { (of all lymphocytes) }\end{array}$ & $7.3(3-31.1)$ & $9.7 \pm 6.4$ \\
\hline $\begin{array}{l}\text { Total lymphocyte \% } \\
\text { (of all events) }\end{array}$ & $5.5(1.1-28.6)$ & $6.7 \pm 5.2$ \\
\hline
\end{tabular}

Abbreviation: AML, acute myeloid leukemia. 
154 Bone Marrow Lymphocyte Subset in AML Dange et al.

Table 2 Comparison of median (and range) of lymphocyte subset with risk stratification of AML (total $n=41$ )

\begin{tabular}{|c|c|c|c|c|c|}
\hline $\begin{array}{l}\text { Lymphocyte } \\
\text { subset }\end{array}$ & Parameter & $\begin{array}{l}\text { Adverse } \\
(n=14)\end{array}$ & $\begin{array}{l}\text { Favorable } \\
(n=14)\end{array}$ & $\begin{array}{l}\text { Intermediate } \\
(n=22)\end{array}$ & $p$-Value \\
\hline \multirow[t]{2}{*}{ CD4:CD8 ratio } & Mean \pm SD & $0.76 \pm 0.26$ & $1.11 \pm 0.43$ & $1.05 \pm 0.32$ & \multirow[t]{2}{*}{0.078} \\
\hline & Median (range) & $0.65(0.47-1.12)$ & $1(0.64-1.94)$ & $0.9(0.42-1.84)$ & \\
\hline \multirow{2}{*}{$\begin{array}{l}\text { CD4 positive } \\
\text { (of all lymphocytes) }\end{array}$} & Mean \pm SD & $29.8 \pm 7.1$ & $30.9 \pm 8.8$ & $31.8 \pm 6.6$ & \multirow[t]{2}{*}{0.855} \\
\hline & Median (range) & $27.5(23.5-40.4)$ & $31.25(16.4-47.3)$ & $31.45(18.1-43.8)$ & \\
\hline \multirow{2}{*}{$\begin{array}{l}\text { CD8 positive } \\
\text { (of all lymphocytes) }\end{array}$} & Mean \pm SD & $40.44 \pm 8.18$ & $30.53 \pm 11.47$ & $32.38 \pm 9.1$ & \multirow[t]{2}{*}{0.168} \\
\hline & Median (range) & $41.8(29.7-51.7)$ & $30.2(15.9-47.5)$ & $32.8(16.2-48.8)$ & \\
\hline \multirow{2}{*}{$\begin{array}{l}\text { NK cells } \\
\text { (of all lymphocytes) }\end{array}$} & Mean \pm SD & $6.8 \pm 3.9$ & $7.5 \pm 4.6$ & $11.7 \pm 7.2$ & \multirow[t]{2}{*}{0.578} \\
\hline & Median (range) & $5.6(3-12.9)$ & $5.8(3.4-19.4)$ & $9.3(4.4-31.1)$ & \\
\hline \multirow{2}{*}{$\begin{array}{l}\text { Total lymphocyte } \\
\text { (of all events) }\end{array}$} & Mean \pm SD & $3.0 \pm 1.7$ & $9.9 \pm 7.1$ & $5.6 \pm 3.2$ & \multirow[t]{2}{*}{0.005} \\
\hline & Median (range) & $3.5(1.2-4.7)$ & $8.35(3.2-28.6)$ & $5.05(1.1-11.4)$ & \\
\hline \multirow[t]{2}{*}{ Bone marrow blast (\%) } & Mean \pm SD & $64.8 \pm 25.1$ & $67.8 \pm 23.1$ & $72.9 \pm 18.1$ & \multirow[t]{2}{*}{0.631} \\
\hline & Median (range) & $72(22-85)$ & $75(24-90)$ & $77.5(28-94)$ & \\
\hline
\end{tabular}

Abbreviation: SD, standard deviation.

Table 3 Comparison of lymphocyte subset in APML vs. non-APML

\begin{tabular}{|c|c|c|c|c|}
\hline Lymphocyte subset & Parameter & PML-RARA negative $(n=33)$ & PML-RARA positive $(n=8)$ & $p$-Value \\
\hline \multirow[t]{2}{*}{ CD4:CD8 ratio } & Mean \pm SD & $0.98 \pm 0.32$ & $1.27 \pm 0.47$ & \multirow[t]{2}{*}{0.11} \\
\hline & Median (range) & $0.88(0.42-1.84)$ & $1.26(0.66-1.94)$ & \\
\hline \multirow{2}{*}{$\begin{array}{l}\text { CD4 positive } \\
\text { (of all lymphocytes) }\end{array}$} & Mean \pm SD & $32.3 \pm 6.6$ & $27.0 \pm 8.9$ & \multirow[t]{2}{*}{0.068} \\
\hline & Median (range) & $32.2(18.1-47.3)$ & $26.1(16.4-44.2)$ & \\
\hline \multirow{2}{*}{$\begin{array}{l}\text { CD8 positive } \\
\text { (of all lymphocytes) }\end{array}$} & Mean \pm SD & $35.2 \pm 9.2$ & $22.4 \pm 6.8$ & \multirow[t]{2}{*}{0.001} \\
\hline & Median (range) & $35.8(16.2-51.7)$ & $20.9(15.9-35.7)$ & \\
\hline \multirow{2}{*}{$\begin{array}{l}\text { NK cells } \\
\text { (of all lymphocytes) }\end{array}$} & Mean \pm SD & $9.9 \pm 6.6$ & $8.9 \pm 5.7$ & \multirow[t]{2}{*}{0.554} \\
\hline & Median (range) & $7.3(3-31.1)$ & $7.1(3.4-19.4)$ & \\
\hline \multirow{2}{*}{$\begin{array}{l}\text { Total lymphocyte } \\
\text { (of all events) }\end{array}$} & Mean \pm SD & $5.4 \pm 3.1$ & $12.4 \pm 8.3$ & \multirow[t]{2}{*}{0.005} \\
\hline & Median (range) & $4.7(1.1-11.9)$ & $9.3(5.3-28.6)$ & \\
\hline
\end{tabular}

Abbreviation: SD, standard deviation.

\section{Discussion}

The important components of tumor-associated immune cells include $\mathrm{T}$ lymphocytes (helper, cytotoxic, regulatory, memory, etc.) and NK cells along with other less characterized cells like tumor associated macrophage and tumor associated neutrophil. ${ }^{5}$ Quantitative as well as functional alteration in lymphocytes plays important role in tumor pathogenesis. ${ }^{6}$ For NK cells, reduced expression of activating receptors and functional impairment in the NK cells help immune evasion. $^{7}$

We studied 41 cases of AML to analyze lymphocyte subset in bone marrow comprising of 23 males and 18 female patients. The median age was 29 years (range: 6-65 years), which is much lower than that described in other studies. ${ }^{8,9}$ One probable reason is the referral bias, wherein, the younger patients eligible for chemotherapy are likely to get referred as compared with older and frail patients who are ineligible for chemotherapy

\section{Lymphocyte Subset Analysis}

$\mathrm{T}$ lymphocytes are the predominant lymphocyte subset in bone marrow in AML patients with almost equal proportion of CD4 and CD8 positive T cells. The proportion of lymphocyte and their subset in the current study are in concordance with another study by Ismail ( - Table 4).$^{10}$ In the present study, the total lymphocyte and the NK cell proportion in AML cases were less than that of the controls ( - Table 4). ${ }^{11}$ The T-cell proportion, however, was comparable to the controls. It is clear that reduction in NK cells is one of the major alterations in treatment naïve AML patients.

APML represents a distinct subtype of AML with a distinct morphology, management, as well as prognosis. Though total lymphocytes were significantly higher in APML subgroup as compared with non-APML AML patients, CD4 and CD8 population was lower in APML, implicating higher number of non-T lymphocytes, i.e., B lymphocytes. The results were concordant with the study by Alcasid et al (- Table 5). ${ }^{12}$ 
Table 4 Comparison of lymphocyte subset with study by Ismail ${ }^{10}$

\begin{tabular}{|l|l|l|l|}
\hline Cell subtype & Ismail $(\boldsymbol{n}=\mathbf{6 6})$ & Control $(\boldsymbol{n}=\mathbf{2 0})$ & Present study $(\boldsymbol{n}=\mathbf{4 1})$ \\
\hline Total lymphocytes & $10.5 \pm 9.2$ & $15.1(6.4-30.7)$ & $6.79 \pm 5.29$ \\
\hline CD4 & $37.9 \pm 13.1$ & $\begin{array}{l}\text { Total T cells } \\
73.5 \%(58.5-90.1 \%)\end{array}$ & $31.28 \pm 7.36$ \\
\hline CD8 & $37.2 \pm 12.0$ & Not mentioned & $32.73 \pm 10.12$ \\
\hline CD4:CD8 & $1.2 \pm 0.6$ & $15.3(3.1-28.0)$ & $1.04 \pm 0.36$ \\
\hline NK cell & $7.9 \pm 4.4$ & & $9.72 \pm 6.43$ \\
\hline
\end{tabular}

Tale 5 Comparison of lymphocyte subset for APML and nonAPML patients

\begin{tabular}{|l|l|l|}
\hline $\begin{array}{l}\text { Parameter for } \\
\text { APML vs. non- } \\
\text { APML patients }\end{array}$ & Alcasid et al $\mathbf{1 2}^{\mathbf{1 2}}$ & Present study \\
\hline NK cells & $\begin{array}{l}\text { Higher than } \\
\text { non-APML } \\
(p=0.03)\end{array}$ & $\begin{array}{l}\text { Not different than } \\
\text { non-APML }\end{array}$ \\
\hline CD4 T cells & $\begin{array}{l}\text { Decreased than } \\
\text { non-APML } \\
(p=0.004)\end{array}$ & $\begin{array}{l}\text { Tend to be decreased } \\
(p=0.06)\end{array}$ \\
\hline Total T cells & $\begin{array}{l}\text { Decreased than } \\
\text { non-APML }\end{array}$ & $\begin{array}{l}\text { Decreased than } \\
\text { non-APML }\end{array}$ \\
\hline CD8 T cells & Not mentioned & $\begin{array}{l}\text { Decreased than } \\
\text { non-APML }(p=0.001)\end{array}$ \\
\hline
\end{tabular}

The cytogenetic and molecular mutation analysis determines the prognostic category of the patient, favorable, intermediate, or adverse risk group. In our study, only total lymphocytes showed a significant trend across the three categories, being highest in the favorable group and least in the adverse group $(p=0.005)$. There was no significant difference in the bone marrow blast percentage among the three categories $(p=0.631)$. Thus, this difference in the lymphocyte proportion cannot be explained by difference in the bone marrow blast percentage. It is possible that lymphocyte-mediated immunity is downregulated in the highrisk category. In another study by Ismail, they did not find any significant difference in total lymphocyte percentage or any of the subset. ${ }^{10}$ On the contrary, Aggarwal et al studied NK cells in AML and found higher proportion of NK cells in poor prognostic group as compared with good prognosis group. $^{11}$

\section{Lymphocyte Subset Analysis and Treatment}

Out of 24 patients, 14 achieved remission while the rest either died $(n=8)$ or were not in remission at the end of the induction $(n=2)$. No significant difference was noted in the baseline bone marrow lymphocyte proportion or any of the subset between the patients who achieved remission or those who died during induction or had a refractory disease. In the study by Ismail, they found significantly higher number of total lymphocytes, T cells, and NK cells in the group that achieved remission $(n=42) .{ }^{10}$ Chuc et al studied lymphocyte subset in 28 AML patients. They, however, expressed the cell subtypes in cells per microliter. Though median follow-up was only 12 months, they found that increased CD4 and CD8 cells are associated with lower overall survival at 1 year. ${ }^{13}$

There were 12 patients for whom both baseline as well as post induction bone marrow were obtained. Total lymphocyte proportion decreased at the end of induction $(p=0.09)$ and CD4 positive helper T cells increased after induction ( $p=$ 0.046 ). Whether the reduction in total lymphocyte is relative (due to brisk regenerating hematopoiesis after the induction therapy) or there is true reduction due to reduced antigen stimulus (due to reduced tumor cells) needs further study with larger sample size. Few studies have studied peripheral blood lymphocytes as a means to assess immune reconstitution. ${ }^{14,15}$ However, the literature on bone marrow lymphocytes post induction therapy is scarce.

Though it is clear that lymphocytes do play a role in the tumor immunity, other important components of immunity like dendritic cells and regulatory $T$ cells were not included in the study. Thus, larger study that combines the quantitative and qualitative/functional aspects of the tumor immunity is needed.

Further larger study assessing the dynamics of lymphocyte proportion at various timelines, like at baseline, at the end of induction, and at the end of consolidation therapy is needed. Study of tumor immunity in the later part of the treatment may shed more light on the role of these immune cells in preventing the relapse.

Reduction in bone marrow total lymphocyte percentage, especially NK cells is the most significant finding in AML patients as well as amongst different risk groups. With emerging role of cellular therapy and immune modulation, the current study highlights the difference in the nature of tumor immunity in cases of AML amongst the risk groups. Larger studies including the functional analysis would be crucial for detailed analysis and development of cellular therapy in AML patients, particularly the high-risk groups.

\section{Presentation}

Data earlier presented at Hematocon 2019, New Delhi. The study was approved by the Institutional Review Board.

\section{Author Contribution}

P.D. contributed toward study design, data collection, and manuscript preparation. S.T. did the study design, data analysis, and manuscript review. R.J. prepared the manuscript. T.S. did the manuscript review and supervision. R.S. did the data analysis, manuscript review, and supervision. 


\section{Funding}

None.

\section{Conflict of Interest \\ None declared.}

\section{References}

1 Swerdlow SH, Campo E, Harris NL, et al. WHO Classification of Tumours of Hematopoietic and Lymphoid Tissues. 4th revised edition Lyon: International Agency for Research on Cancer; 2017: 585

2 Estey EH. Acute myeloid leukemia: 2019 update on risk-stratification and management. Am J Hematol 2018;93(10):1267-1291

3 Shafat MS, Gnaneswaran B, Bowles KM, Rushworth SA. The bone marrow microenvironment-home of the leukemic blasts. Blood Rev 2017;31(05):277-286

4 Zitvogel L, Apetoh L, Ghiringhelli F, André F, Tesniere A, Kroemer $G$. The anticancer immune response: indispensable for therapeutic success? J Clin Invest 2008;118(06):1991-2001

5 Gbolahan OB, Zeidan AM, Stahl M, et al. Immunotherapeutic concepts to target acute myeloid leukemia: focusing on the role of monoclonal antibodies, hypomethylating agents and the leukemic microenvironment. Int J Mol Sci 2017;18(08):E1660

6 Vivier E, Tomasello E, Baratin M, Walzer T, Ugolini S. Functions of natural killer cells. Nat Immunol 2008;9(05):503-510

7 Woo JR, Liss MA, Muldong MT, et al. Tumor infiltrating B-cells are increased in prostate cancer tissue. J Transl Med 2014;12:30
8 Acute Myeloid Leukemia-Cancer Stat Facts. SEER. Accessed August 17, 2019 at: https://seer.cancer.gov/statfacts/html/amyl. html

9 De Kouchkovsky I, Abdul-Hay M. 'Acute myeloid leukemia: a comprehensive review and 2016 update'. Blood Cancer J 2016; 6(07):e441

10 Ismail MM, Abdulateef NAB. Bone marrow T-cell percentage: a novel prognostic indicator in acute myeloid leukemia. Int J Hematol 2017;105(04):453-464

11 Aggarwal N, Swerdlow SH, TenEyck SP, Boyiadzis M, Felgar RE. Natural killer cell (NK) subsets and NK-like T-cell populations in acute myeloid leukemias and myelodysplastic syndromes. Cytometry B Clin Cytom 2016;90(04):349-357

12 Alcasid M, Ma L, Gotlib JR, Arber DA, Ohgami RS. The clinicopathologic significance of lymphocyte subsets in acute myeloid leukemia. Int J Lab Hematol 2017;39(02):129-136

13 Najera Chuc AE, Cervantes LAM, Retiguin FP, Ojeda JV, Maldonado ER. Low number of invariant NKT cells is associated with poor survival in acute myeloid leukemia. J Cancer Res Clin Oncol 2012; 138(08):1427-1432

14 De Angulo G, Yuen C, Palla SL, Anderson PM, Zweidler-McKay PA. Absolute lymphocyte count is a novel prognostic indicator in ALL and AML: implications for risk stratification and future studies. Cancer 2008;112(02):407-415

15 Behl D, Porrata LF, Markovic SN, et al. Absolute lymphocyte count recovery after induction chemotherapy predicts superior survival in acute myelogenous leukemia. Leukemia 2006;20(01): 29-34 